La miniatura lombarda se configura a lo largo del siglo xIv bajo la influencia de la escuela boloñesa. A finales de siglo el mecenazgo de los Visconti abre el arte lombardo a los influjos transalpinos y supone para la iluminación de libros un momento de gran esplendor. Entre los iluminadores destacan a finales de siglo Giovannino de Grassi y Michelino da Besozzo. De la obra de ambos, dentro del gótico internacional, derivan los maestros anónimos de la primera mitad del siglo xv como el Maestro de las Vitae Imperatorum, el Maestro del Breviario Franciscano y el Maestro del Antifonario de Budapest.

Podemos encuadrar nuestra miniatura dentro del círculo del Maestro de las Vitae Imperatorum, nombre acuñado por Pietro Toesca a partir del códice de Suetonio de la Bibliothèque Nationale de París (ms. it. 131), realizado en 1431 para Filippo Maria Visconti ${ }^{13}$. Trabajó en una numerosa serie de manuscritos entre 1408 y 1459, de los que en España sólo se ha identificado un códice con las Sátiras de Filelfo, fechado en 1453 (Valencia, Biblioteca General de la Universidad, Ms. 398). Su estilo, que ha sido confundido en alguna ocasión con el de otros maestros, tuvo gran influencia en la miniatura lombarda del siglo xv. Se caracteriza por los tipos humanos de rostros descarnados con los ojos muy marcados, colorido fuerte y contrastado, y fondos lisos con decoraciones vegetales. Todos estos rasgos aparecen en esta miniatura, que, sin embargo, no creemos que sea obra del propio maestro sino de algún seguidor, que también realizó un fragmento de un antifonario conservado en la Free Library de Filadelfia (M.27.21). Representa la Entrada de Cristo en Jerusalén, mide $190 \times 140 \mathrm{~mm}$ y se desconoce su origen ${ }^{14}$. Ambos fragmentos comparten, además de la decoración del fondo de la escena ya señalada, unos personajes con rasgos similares y detalles peculiares como los dedos de remate puntiagudo. Asimismo la técnica empleada es parecida ya que en los dos casos las líneas del tetragrama subyacente afloran en la miniatura. Por su estilo pueden fecharse en los años centrales del siglo xv, más concretamente en el período 1445-1450, momento en el que, según Anna Melograni 15, los códices de este taller muestran una técnica más acuarelada y menos cubriente.

F. JAVIER DocAmpo Biblioteca Nacional

\title{
MÚSICA Y RETÓRICA EN LA ALEGORÍA DEL OÍDO DE JAN BRUEGHEL «DE VELOURS» Y RUBENS
}

La Alegoría del oído es una tabla sin firma, pintada hacia 1617 por Jan Brueghel (1568$1625)$ en colaboración con Pedro Pablo Rubens (1577-1640). Forma parte de una colección sobre los cinco sentidos realizada para los Archiduques de Austria que se custodia actualmente en

13 Toesca, P., La pittura e la miniatura nella Lombardia dai piú antichi monumenti alla metà del Quattrocento, Milán, 1912 , p. 529. Sobre este maestro véase además Stefani, Letizia, "Per una storia della miniatura lombarda da Giovannino de Grassi alla scuola cremonese della II metà del quattrocento: appunti bibliografici", en La miniatura italiana tra Gotico e Rinascimento: atti del II Congresso di Storia della Miniatura Italiana, Florencia, 1985, pp. 838-841 y 875-881; Stones, Alison, "An italian miniature in the Gambier-Parry collection" en The Burlington Magazine, CXI, 1969, pp. 7-12; Toesca, Ilaria, "In margine al Maestro delle Vitae Imperatorum» en Paragone, XX, n. ${ }^{\circ} 237,1969$, pp. 73-77 y Melograni, Anna, "Appunti di miniatura lombarda: ricerche sul Maestro delle Vitae Imperatorum», en Storia dell'Arte, n. ${ }^{\circ}$ 170, 1990, pp. $274-314$.

14 Daneu Lattanzi, Angela, "La miniatura nella Italia Meridionale» en La miniatura italiana tra gotico e rinascimento: atti del II Congresso di Storia della Miniatura italiana, Florencia, 1985, pp. 775-776, fig. 16. Agradezco a Karen Lightner, de la Free Library, las informaciones proporcionadas sobre este fragmento.

15 Melograni, Anna, Op. cit., pp. 296-98. 
el Museo del Prado. Brueghel entró al servicio de los Archiduques como pintor de cámara en 1609, recién firmada la Tregua de los Doce Años. Las obras de Brueghel realizadas durante este período ponen de relieve las virtudes que la paz y el buen gobierno de los Archiduques. El programa pictórico de los cinco sentidos es un canto a la paz a través de la abundancia (con las estaciones y los elementos), la armonía apolínea (con el patrocinio de las artes y los oficios) y la confianza en la fe católica. La serie trata aparentemente un tema humano pero presenta claras alusiones morales y religiosas: la guerra había tenido connotaciones religiosas y el Archiduque había ocupado antes de su matrimonio el puesto de cardenal y arzobispo de Toledo. La conexión entre el tema de la abundancia y los cinco sentidos se hace patente en el cuadro sobre Los cuatro elementos, de Jan Brueghel «El Joven» (1601-1625) y Hendrick van Balen (1575-1632) que Aída Padrón ${ }^{1}$ relaciona con los sentidos y las estaciones dentro de una compleja visión iconográfica, propia de la época.

La alegoría del oído nos muestra, sobre una rica alfombra y en lugar central, una ninfa desnuda cantando y tocando el laúd, con un amorcillo que sostiene la partitura (Fig. 1). Junto a estas figuras, aparecen también un ciervo y un lince. Señala Díaz Padrón ${ }^{2}$ que según SpethHolterhoff se trata de la musa Euterpe, mientras que para Mirimonde representa a la diosa Venus. Aunque dichas interpretaciones no son incompatibles, Cesare Ripa señala en su Iconología (1593) que el oído se representa como una «mujer que toca el laúd a cuyo lado se ha de pintar una cierva" ' ${ }^{3}$. En los grabados de Cornelius Cort sobre dibujos de Frans Floris ${ }^{4}$, realizados en 1561, encontramos un temprano ejemplo que se corresponde exactamente con esta descripción. Los bestiarios nos dicen que los ciervos comen serpientes y que por lo tanto son enemigos seculares del mal, igual que el águila y el león ${ }^{5}$. Los ciervos son además mensajeros de los dioses y símbolos de longevidad ${ }^{6}$ y resurrección, porque supuestamente mudan de piel. Su cornamenta nos recuerda el lignum crucis y el árbol de la vida 7 . El ciervo representa el oído agudo como en otros casos lo hace el topo. En la pintura de Tiziano titulada $\mathrm{Ve}$ nus recreándose con el Amor y la Música (post. 1548) encontramos un ciervo en el jardín, detrás del órgano.

El lince o lobo cerval es el animal de vista más fina e incluso es capaz de ver a través de rocas, paredes y objetos opacos. Su presencia bajo el asiento y manto de la alegoría del oído tal vez signifique la superioridad del oído sobre la vista en asuntos de amor, como le ocurrió a Don Quijote, enamorado «de oídas» de la fama de Dulcinea; ya se sabe que el Amor es ciego, que Cupido suele llevar una venda sobre sus ojos y que el oído es la puerta del amor. Ripa abunda en el idealismo platónico al tratar el "Origen del Amor» 8: La referencia a la lírica amorosa explica la presencia de Cupido, cuyas alas se adivinan, aunque no aparecen en Brueghel ni las flechas ni la

\footnotetext{
1 “Una réplica de Jan Brueghel el Joven de Los sentidos y los elementos del Museo del Prado» en Boletín del Museo del Prado, tomo XVI, n. ${ }^{\circ} 34,1995$, pp. 15 a 20.

2 Díaz Padrón, Matías, Museo del Prado. Catálogo de Pinturas. I. Escuela Flamenca. Siglo xvII, 2 vols., Patronato Nacional de Museos, Madrid, 1975, 501 (textos) y 335 (láminas) Ver, p. 43. Cfr. Speth-Holterhoff, S., Les peintres flamands de gabinet d'amateurs au XVII siècle, 1957. Mirimonde, A. P. de, "La Musique dans les allégories de l'Amour», en Gazette des Beaux Arts, 1966, tomo II, pp. 265 a 290. Relaciona el gato (el lince) con el erotismo como atributo de Venus.

3 Ripa, Cesare, "Los sentidos del cuerpo» en Iconología, editorial Akal, Torrejón de Ardoz, Madrid, 1987, 2 vols., 592 y 463 pp. Ver vol. II, p. 304 y ss.

4 Sabán Godoy, Montserrat (coordinadora), Los cincos sentidos y el arte, catálogo de la exposición, Museo del Prado, Ministerio de Educación y Cultura, Madrid, 1996, 397 pp. Ver p. 110.

5 Malaxecheverría, Ignacio, Bestiario Medieval, Siruela, Madrid, 1986, 292 pp. Ver pp. 18 y ss. («El lince y el topo») y 42 y ss. ("Ciervos»).

6 Alciato, Emblemas, edición de Santiago Sebastián, Akal, Madrid, 1993, 278 pp. Ver vol. II, p. 411 y ss., "Vida larga».

7 Cirlot, Juan-Eduardo, "Alegorías» en Diccionario de símbolos, Labor, Barcelona, 1982, 475 pp. Véase pp. 128 a 130.

8 Ripa, Op. cit., ver p. 162 y ss. Ibn Hazm de Córdoba, El collar de la paloma, versión de Emilio García Gómez, Alianza Editorial, Madrid, 1971, 355 pp. Ver p. 121 y ss.
} 


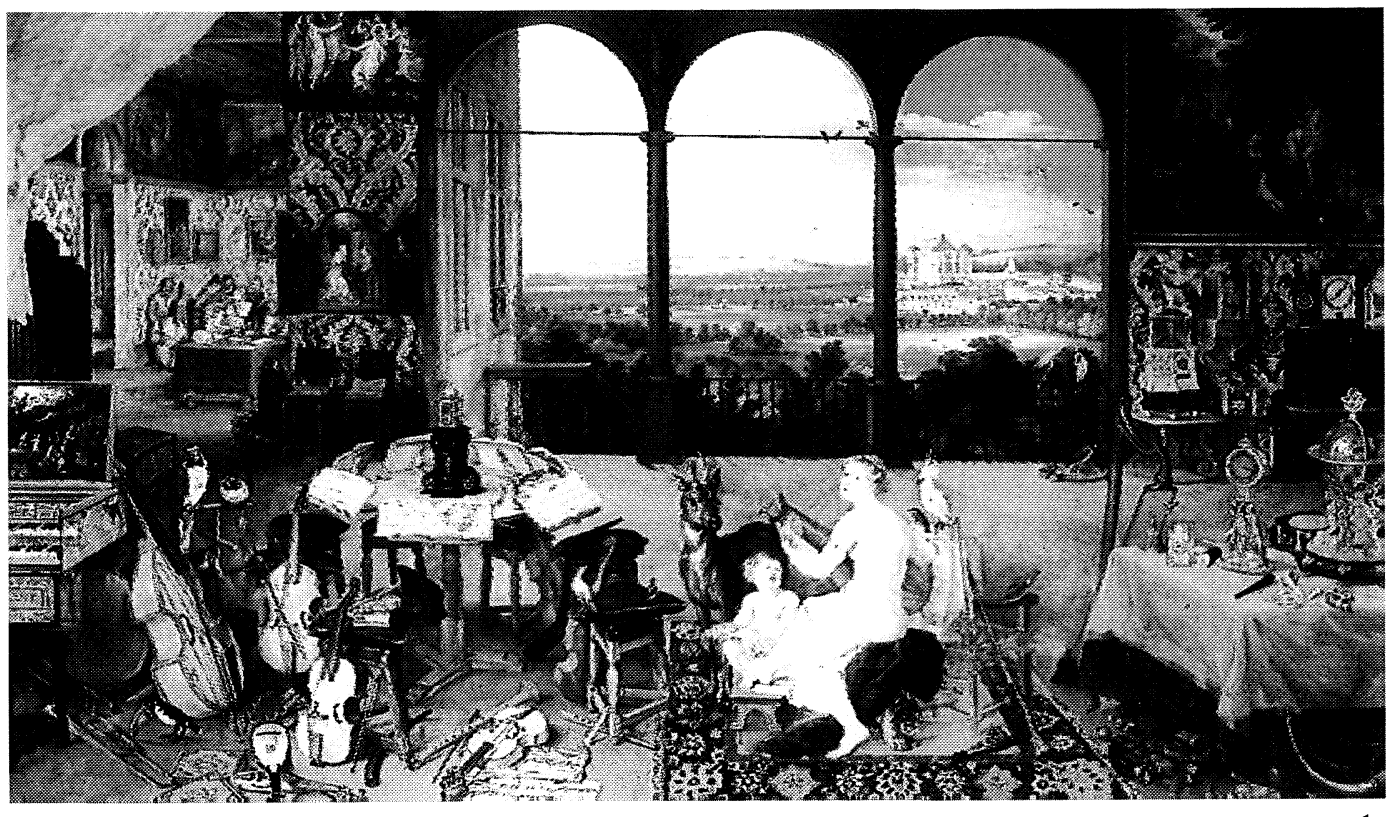

$2 \mathrm{a}$
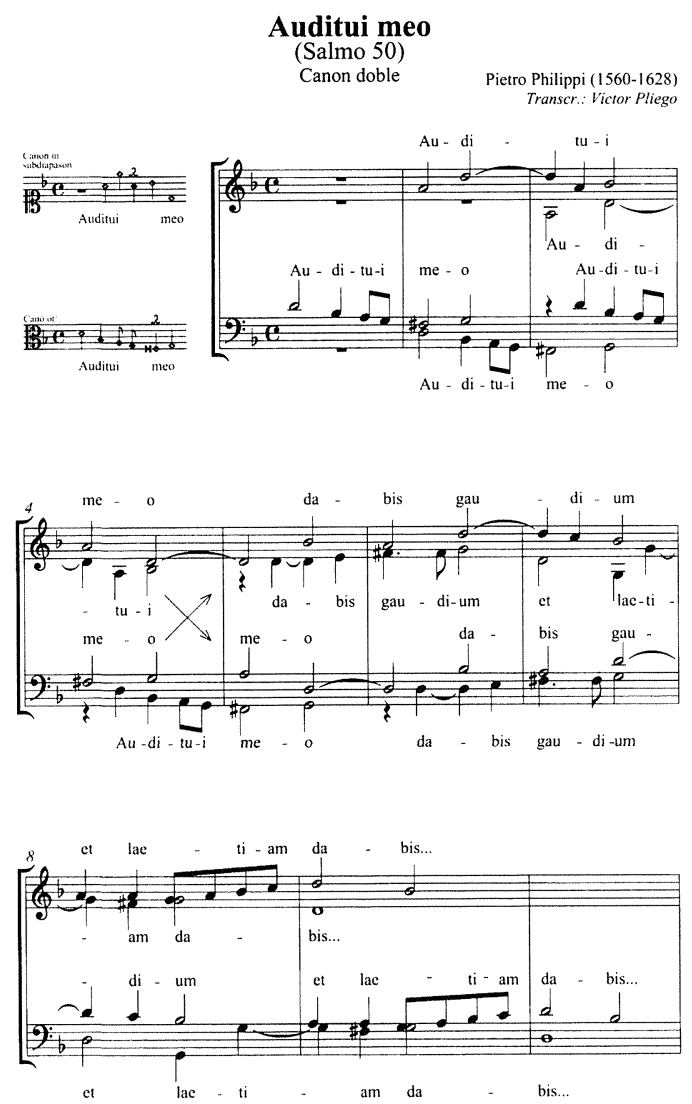

$2 b$
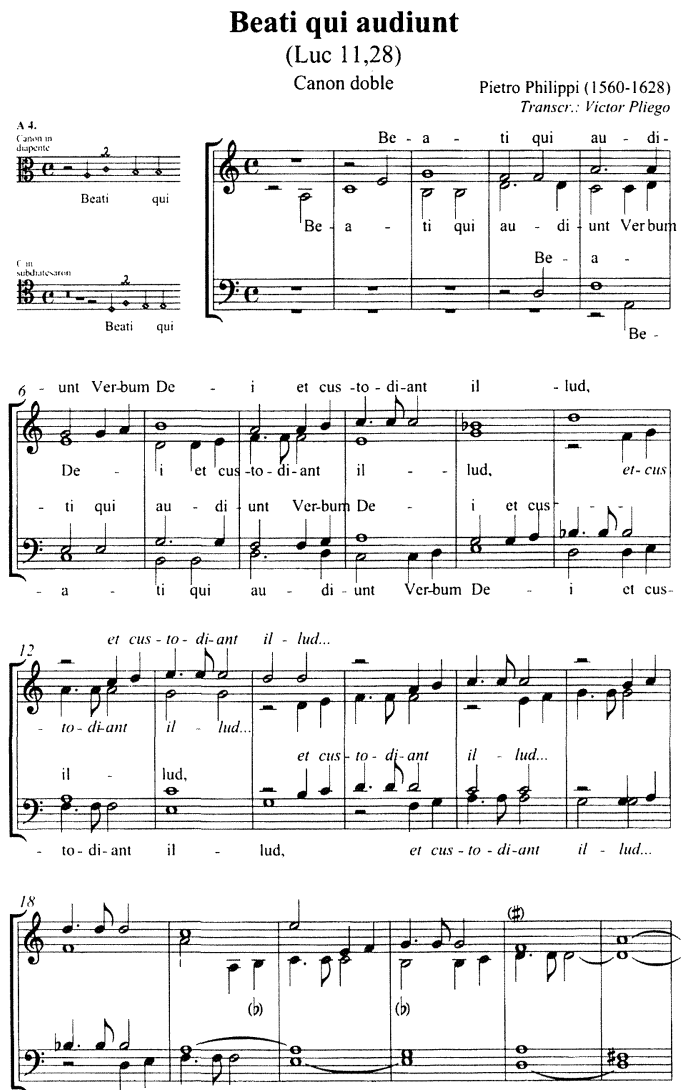

Fig. 1. Brueghel "de Velours» y Rubens, Alegoría del Oído. Madrid, Museo del Prado.

Fig. 2. Resolución de los cánones que aparecen representados en la Alegoría del Oído, de Brueghel y Rubens (Madrid, Museo del Prado) en (a) un libro abierto y (b) en una hoja. 
antorcha. Este detalle nos recuerda el Amor Virtutis que Alciato nos presenta en su Emblema CIX ${ }^{9}$.

Junto a los textos religiosos de las partituras (Salmo 50,10 y Luc 11,28), encontramos además una iconografía con la palabra divina y su escucha como protagonistas. Es el mensaje oral oído que completa el ciclo de profecías que culmina con el nacimiento de Cristo. A la izquierda de la galería aparece un tríptico que representa la Anunciación a la Virgen María (Luc 1,26-38). Se trata el mensaje divino que se transmite a través de la voz del Arcángel Gabriel al oído de María. Al pie del tríptico, una joven dama ora junto a un perro, símbolo de la fidelidad a María.

El reloj de la mesa de la izquierda tiene en su zócalo una hornacina con una figurita de San Juan Bautista a quien reconocemos por su cruz característica. Es «la voz que clama en el desierto" y profetiza la llegada del Reino de los Cielos (Mat 3; Mar 1; Luc 3) y la hora de la Salvación. En las alegorías cristianas relacionadas con los cinco sentidos, la predicación de San Juan se asocia al oído ${ }^{10}$. En el Museo del Prado encontramos además una pintura de Jan Brueghel que representa a San Juan Predicando ${ }^{11}$. No podemos tampoco olvidar el himno a San Juan Bautista ${ }^{12}$, que da nombre a las notas del hexacordo guidoniano.

La tapa del clavicémbalo está decorada con una escena que representa el anuncio del Nacimiento a los pastores (Luc 2,8-14). Es de nuevo la palabra divina, a traves de la voz de un ángel, la que pregona la buena nueva. La comunicación oral tiene un importante significado teológico puesto que el acontecimiento es comunicado de oídas a los pastores, que se sorprenden y aterrorizan con la celeste aparición. En ese momento se abren los cielos y los coros celestiales entonan el Gloria in excelsis Deo. En el gabinete del fondo hay representada una pintura poco clara con la Adoración de los Reyes (Mat 2), que cierra el ciclo confirmando ante la humanidad que la palabra se ha hecho carne y que ha llegado la hora de la Salvación.

La pintura de Brueghel contiene reproducciones de otras pinturas alegóricas sobre mitos paganos relacionados con la música y el oído dentro de un contexto moralizador y educativo. La gran pintura del ángulo superior derecho representa a Orfeo retirado en el monte Ródope, encantando a las fieras salvajes, a las aves y a las plantas con su música. Es reducción del original del mismo Jan Brueghel que se guarda en la Galería Borghese ${ }^{13}$. El tema de la armonía entre el hombre y las fieras tiene un tratamiento parecido al que podemos observar en otras pinturas de Brueghel ${ }^{14}$ y de su escuela ${ }^{15}$ sobre el Paraíso terrenal y sobre la Entrada de los animales en el Arca de Noé ${ }^{16}$. La escena de Orfeo en Ródope representa la virtud de la continencia y el poder de la elocuencia musical sobre las fuerzas irracionales. Es por ello, según una medalla de Marco Antonio que refiere Ripa ${ }^{17}$, una imagen de la elocuencia ética. Además Orfeo vence con la música a la muerte igual que David o Jesucristo ${ }^{18}$.

En el lado izquierdo aparece un cuadro de Minerva, con túnica roja, casco y lanza, rodeada

9 Alciato, Op. cit. Véase p. 145.

10 Sebastián, Santiago, «El hombre: los cinco sentidos» en Emblemática e historia del arte, Cátedra, Madrid, 1995, 335 pp. Véase p. 121.

11 Número de inventario del Museo del Prado: 1412.

12 Antiphonale Monasticum, p. 922, Festa Junii. 24. Ut queant laxis / REesonare fibris / MIra gestorum / FAmuli tuorum. / SOLve polluti / LAbii reatum / Sancte Joannes.

13 Diáz Padrón, Op. cit. Ver p. 43.

14 El Paraíso terrenal. Número de inventario del Museo del Prado: 1410. Reproduce los mismos guacamayos que encontramos en la Alegoría del oído.

15 Números de inventario del Museo del Prado: 1406 y 1452. Este último es de Jan Brueghel II y consta de un breve programa narrativo que podemos relacionar con el oído. (Núm. 1408).

16 Número de inventario del Museo del Prado: 1407.

17 Ripa, Op. cit., vol. I, p. 315.

18 Revilla, Federico, Diccionario de iconología y simbología, Cátedra, Madrid, 1995, 439 pp. Véase pp. 126 y 306. 
de las nueve musas ${ }^{19}$ que bailan, cantan y tocan diversos instrumentos. Las musas patrocinan las ciencias y las artes, inspiran a los músicos y poetas y representan la armonía musical del conocimiento universal. En la alcoba hay un cuadro en el cual, bajo un gran árbol, un personaje toca el violín y un fauno la flauta en presencia de un juez. Seguramente es una representación del combate entre Marsias y Apolo, entre el género lírico y el género dionisíaco. El cuadro central superior que hay en la alcoba pinta una mujer corriendo por los aires mientras toca una trompa y lleva otra en la mano. Se trata de la Fama, que tanto debe a los oídos dispuestos. Lleva el velo recogido a media pierna como señala Ripa, autor que nos advierte que la trompa «significa el grito o renombre universal esparcido por las orejas de los hombres.» ${ }^{20}$ La Fama tiene dos trompas, ya que proclama indiscriminadamente la verdad y la mentira, y toma prestado de Mercurio el casco alado ${ }^{21}$. También encontramos una fama en el relieve que hay sobre una ménsula en la enjuta de la derecha. En la enjuta complementaria vemos un personaje que toca el cuerno y porta una lanza. El tercer cuadro superior de la alcoba representa una nave llegando a un puerto. Pudiera ser una representación el mito del músico Arión ${ }^{22}$, que salvó la vida cabalgando sobre un delfín gobernado por su música.

En el espacio pictórico principal suenan algunos instrumentos mientras otros yacen silenciosos. Desde la alcoba trasera de la izquierda llegan los acordes de un concierto de música reservata. Vemos allí un grupo de tres damas acompañadas por viola de gamba, laúd, oboe (o corneta) y flauta alemana, que hoy decimos travesera. Interpretan tal vez un madrigal dialogado o alguna pieza con continuo, o bien una obra polifónica más antigua, doblando voces con instrumentos. Unos niños escuchan con atención y curiosidad detrás de la mesa.

Por una ventana, a la izquierda, vemos aparecer los pabellones de dos trompetas naturales, símbolos de autoridad, lanzando toques heráldicos de música alta hacia el espacio exterior. Se observa la curva de una y la otra tal vez sea recta. Los trompeteros quedan ocultos y el punto de vista nos sitúa fuera del gabinete en el que nos hallamos, para contemplar un muro exterior y oír la resonancia de las fanfarrias al aire libre. Quizá lanzan algún mensaje hacia el castillo de Mariemont, situado allá en la lontananza. A estas músicas de fondo se suman el canto del amorcillo y la ninfa, que se acompaña de otro laúd.

La pintura del oído nos presenta tres espacios sonoros: la alcoba del fondo, el gabinete principal y el paisaje que se ve a través del balcón formado por tres arcos de medio punto. Estos espacios están perfectamente comunicados, son de distinto tamaño y contienen sus propios sonidos, producidos por distintas fuentes. En la alcoba hallamos el grupo de músicos y cantantes; en el gabinete, la ninfa con su acompañante, los mecanismos y sonerías de los relojes y las voces de las aves; en el paisaje abierto suenan otras aves y unas trompetas. También podemos imaginar el ruido de los disparos de unos cazadores que persiguen a caballo un ciervo, en un claro delante del castillo lejano, desde el cual tal vez llegan voces y músicas recíprocas. A través del arco central podemos ver, en los aledaños del castillo, unos cañones disparando salvas de honor como celebración pacífica. El cielo está un poco encapotado y resta luz al mediodía (los relojes marcan la una y media): el sonido del viento y de algún trueno lejano también se puede añadir, anunciando una próxima tormenta.

La pintura del oído nos presenta además un excelente y completo catálogo de instrumentos ${ }^{23}$

19 Díaz Padrón, Op. cit. (Véase p. 64). Cfr. Mirimonde, "Les concerts des muses chez les Maîtres du Nord" en Gazette des Beaux Arts, 1964, pp. 133 a 148.

20 Ripa, Op. cit., vol. I, pp. 395 a 397.

21 Revilla, Op. cit., p. 166.

22 Graves, Robert, Los mitos griegos, 2 vols., Alianza Editorial, Madrid, 1985. Vol. I, pp. 360 a 363.

23 Díaz Padrón, Op. cit. (Véase p. 43). Encontramos una detallada relación en Sopeña Ibáñez, Federico; Gallego Gallego, Antonio, La música en el Museo del Prado, Patronato Nacional de Museos, Madrid, 1972, 308 pp. Ver pp. 146 y ss. 
que podemos identificar con total precisión utilizando la rica fuente iconográfica del Syntagma musicum II: De organographia de Michael Praetorius (h. 1571-1621), publicado en Wolffenbüttel en $1615^{24}$, prácticamente a la par que Brueghel pinta su serie de los sentidos (Fig. 3). Existe entre ambas obras una clara coincidencia. Probablemente la intención del pintor no era otra que presentar ante nuestros ojos un rico catálogo de instrumentos musicales para manifestar la riqueza, sensibilidad y mecenazgo de los Archiduques, pero también podemos hacer una interpretación simbólica de ellos.
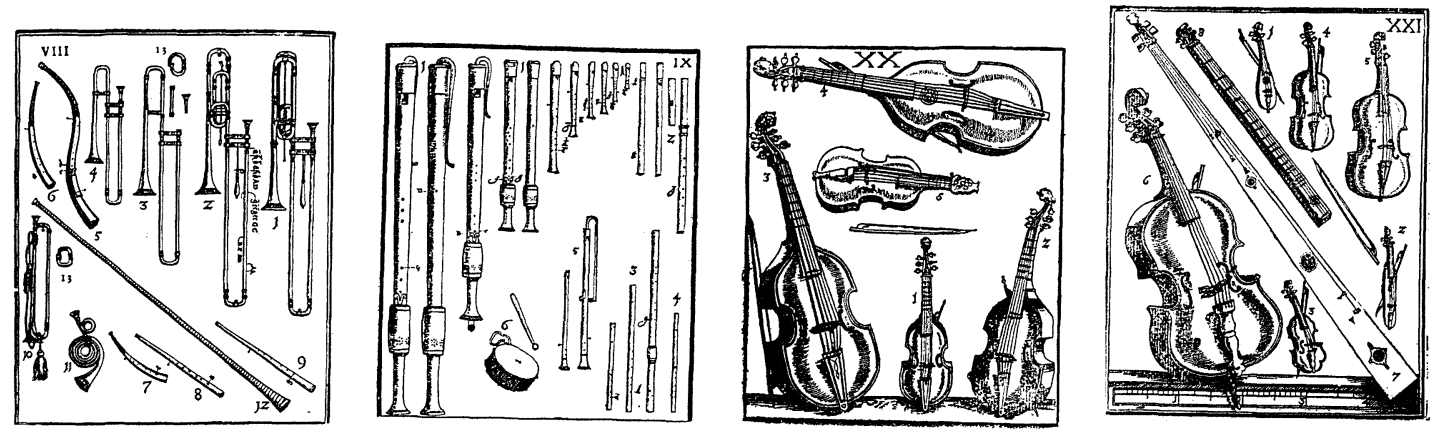

Fig. 3. Laminas con instrumentos musicales del Syntagma Musicum, II: De Organografía de Michael Praetorius (Wolffenbüttel, 1615).

Los instrumentos de cuerda y tecla son los más nobles y adecuados para acompañar la voz. Son apropiados para la música religiosa y de cámara. Permiten acompañar canciones, salvaguardando la semanticidad de la obra musical y por lo tanto su sentido intelectual y moral (la lira y sus parientes son los instrumentos de Apolo). Precisamente, en dos de los tres grupos de músicos encontramos el laúd como instrumento principal y es el que tañe la misma ninfa que representa al oído. El laúd es el instrumento cortesano por excelencia y aparece frecuentemente en la iconografía como símbolo de concordia, paz y armonía, salvo que tenga alguna cuerda rota. Así lo presenta Alciato como símbolo de las alianzas en su emblema $\mathrm{X}^{25}$, y con el mismo sentido se incorpora al cuadro Los embajadores pintado en 1533 por Hans Holbein "El Joven». Jacob Joardens se retrata con su familia con un laúd en la mano en 1621 queriendo significar igualmente la armonía matrimonial.

Los instrumentos de viento y percusión son más propios de la música militar y cinegéntica. Se funden peor con las voces, con el logos, y por lo tanto comunican con las fuerzas más primitivas e irracionales. Predomina en ellos el impulso rítmico y dinámico que lleva al éxtasis. Las trompetas que tocan por la ventana son señal de fuerza y de poder. La autoridad, ya sea militar o

24 Praetorius, Michael, Syntagma musicum II: De organographia, translated and edited by David Z. Crookes, Clarendon Press, Oxford, 1986, 102 pp. con láminas facsimilares de los instrumentos. Pedrell, Felipe, Emporio científico e histórico de organografía musical antigua española, Juan Gili, Barcelona, 1901, 147 pp. Munrow, David, Musikinstrumente des Mittelalters und der Renaissance, Moeck Verlag, Celle, 1980,152 pp.

Los instrumentos silenciosos que encontramos son un órgano positivo, un clavicémbalo, cinco violas da gamba (dos altos, dos tenores y un bajo), un violín pochette, un violín de discanto polilobulado, una lira da braccio, un laúd, una madora, un arpa, una flauta tenor, una soprano de marfil, otras flautas en un estuche, una chirimía discanto, un silbato, dos reclamos de caza, un sacabuche, tres cornetas, una tuerta, una recta y una tenor (lisarda), tres cuernos, uno de ellos de bronce, una trompa francesa, una inglesa y otra de correo, un tambor militar, dos campanas, dos campanillas, dos cencerros y nueve cascabeles. Por otro lado, están cantando y tocando un laúd, dos trompetas, una flauta alemana, un oboe, otro laúd y una viola, como se indicó antes.

25 Alciato, Op. cit., p. 40. 
taurina, se arropa con el ruido de las fanfarrias. El poder de las trompetas destruyó las murallas de Jericó. Las flautas son, por el contrario, instrumentos populares, de pastores y aldeanos. Tienen que ver con la fertilidad masculina (y los tambores con la femenina). Los faunos y sátiros tañen flautas de distintas formas, mientras que las bacantes tocan tambores hechos con pieles de hombres y fieras salvajes. Todos ellos pertenecen al cortejo de Dionisio, mientras que los acompañantes de su antagonista, Apolo, prefieren los instrumentos heroicos de cuerda. En la iconografía cristiana, las virtudes de los ángeles y otras criaturas celestes se representan con la lira, mientras que los diablos, que son parientes directos de los faunos, seguramente prefieren tocar excitantes tambores y flautas lasciva, como ocurre en la célebre égloga de Mallarmé musicada por Debussy. Las flautas se comunican con las fuerzas subterráneas e irracionales y pueden producir olvido de la razón y encantamientos maléficos o misteriosos.

La música no sólo aparece representada a través de diversas fuentes sonoras. También la escritura es música callada y silenciosa que discurre en el pensamiento. Seis son las partituras que aparecen, todas ellas aparentemente de música vocal. No se reconoce una música instrumental específica y cabe suponer que el papel que se otorga a los abundantes instrumentos es el de acompañantes o repetidores. En su representación de la música, Ripa indica que «el libro de música muestra (...) la regla cierta y verdadera que puede utilizarse para participar a los otros de dichas armonías, haciéndolo de forma que puedan penetrarlos por los ojos» ${ }^{26}$.

En primer lugar, destacan los libros de música que hay sobre la mesa en siete atriles. Son el Secondo libro de Madrigali a sei voci, de Pietro Philippi "Inglese» (1560-1628), organista de los Archiduques de Austria. Aunque la fecha es ilegible en el cuadro, sabemos que dicho libro fue publicado en Amberes en 1602, primera edición, y en 1612, en segunda ${ }^{27}$. En otro lugar, en el suelo delante de la mesa, vemos tres libros con una bella encuadernación roja. Dos de ellos están cerrados y atados. En un tercero de distinto formato, abierto bajo la lira da braccio, leemos un canon doble in Subdiapason cuyo texto es el décimo versículo del salmo 50, Miserere mei Deus: Auditui meo dabis gaudium et laetiam dabis (Fig. 2a).Además, en primera línea encontramos una hoja de música suelta que presenta un doble canon a cuatro para resolver desde el alto in Diapente y desde el tenor in Subdiatessaron con el siguiente texto latino del Evangelio de Lucas (Luc 11,28): Beati qui audiunt verbum Dei et custodiant illud (Fig. 2b) ${ }^{28}$.

La cuarta partitura es un libro grueso y de pequeño formato, tal vez un gradual, que reposa en una banqueta debajo del violín de discanto. Aunque predomina la música profana y madrigalesca, el género religioso tiene una sutil presencia en este salón, con textos bíblicos que afirman el valor oral y auditivo de la palabra divina. Las dos partituras que restan son las que tañen los dos grupos de intérpretes: el de la alcoba y el de los personajes alegóricos centrales.

En la pintura de Brueghel los pájaros también representan la música ${ }^{29}$, el aire, las voces de los animales e incluso, por su capacidad de imitación en ciertos casos, las de los hombres. Su canto es un sonido de la naturaleza que se parece a la música pero que no se confunde con ella. Las teorías imitativas del Barroco tomaron finalmente como referencia musical las inflexiones

26 Ripa, Op. cit., vol. II, p. 119.

27 Steele, John, «Philips» en The New Grove Dictionary, vol. 14.

28 Agradezco a Juan Carlos Asensio, Catedrático de Canto Gregoriano del Conservatorio de Salamanca, la identificación de estos textos.

29 En el interior: dos tucanes (ramphastos tucanus) de Brasil, dos guacamayos azules con pecho amarillo (ara arauna), un jilguero (carduelis carduelis), un joven estornino o una alondra común (alauda arvensis), una collalba gris (oenanthe oenanthe), un ruiseñor común (luscina megarhynchos), una cacatúa blanca con cresta amarilla (kakatoë galerita), un ruiseñor azul de Norteamérica (sialia sialis), un loro gris africano con cola roja (psittacus erithacus) y dos guacamayos rojos (ara militaris).

En la parte exterior, a través de las ventanas vemos: Varias urracas (pica pica), golondrinas comunes (hirundo rustica), aviones comunes volando (delichon urbica), gorriones comunes (passer domesticus), dos garzas reales (ardea cinerea), un carrán común (stema hirudo) y dos vencejos comunes (apus apus). 
del habla humana, que es el sonido significativo por excelencia. El estilo representativo de la ópera, inventado en la camerata fiorentina a principios del siglo xVII, imita los acentos y las inflexiones del habla. La música sin apoyo ni significado verbal es sólo un dulce y agradable entretenimiento para el oído, igual que el canto de las aves, que no tendrá plena aceptación hasta mediado el Siglo de las Luces.

La presencia de las aves migratorias nos permite situar la escena en primavera o, por las nubes y el color de los campos, a comienzos del verano de 1617. Alciato relaciona en el Emblema $C$ las cuatro estaciones con los pájaros: «El pinzón anuncia que ha llegado el invierno. La gorgojeante golondrina nos devuelve la primavera. El cuclillo indica que aguarda el verano. En otoño sólo se ven grajos» ${ }^{30}$.

Al igual que la música, los pájaros se elevan hacia los cielos y simbolizan la imaginación, los espíritus y las almas de los difuntos ${ }^{31}$. Los pájaros parlantes, el loro sobre todo y también los guacamayos y la cacatúa, parodian el habla humana y la elocuencia ${ }^{32}$. Cesare Ripa coloca al papagayo como atributo de la elocuencia ${ }^{33}$. Las aves canoras, como el ruiseñor y el jilguero, representan la inspiración musical. Una de las alegorías de la música que propone Ripa aparece con un ruiseñor en la cabeza. ${ }^{34} \mathrm{El}$ ruiseñor también puede apelar a la crueldad, ${ }^{35}$ en referencia al mito de Filomela que, para vengarse del cuñado que la atacó, mató con su hermana al hijo de aquel y se lo sirvió en un banquete. La golondrina es el símbolo de la amistad no correspondida y del llanto ${ }^{36}$. También puede ser, igual que el gorrión, símbolo de la convivencia ${ }^{37}$ entre los hombres, porque reparte equitativamente el alimento entre sus polluelos. Con este significado maternal y doloroso encontramos una golondrina en la tabla de La Anunciación de Fra Angelico. La garza y la cigüeña suelen representar la fecundidad y el amor paterno.

El oído existe en la memoria y la memoria camina por el tiempo. Los relojes vinculan la música con el tiempo y el ritmo. Podemos imaginar el sonido del tic-tac y de las campanas de estos relojes, como el de un metrónomo que marcase el tactus, es decir, la pulsación musical que mide el tiempo en el gabinete de los Archiduques. El tiempo rige la música y así encontramos la figura alada de Cronos, con la guadaña, un reloj de arena y otro de esfera, culminando el Templo de la Música con el que Robert Fludd ilustra un tratado publicado en $1617{ }^{38}$.

Debe ser aproximadamente la una y media del mediodía, aunque la luz es dudosa a causa de los nubarrones ${ }^{39}$. Doce son los relojes que aparecen, casi todos de mesa ${ }^{40}$. Según Díaz Padrón ${ }^{41}$ la presencia de los relojes nos recuerda que la música es una vanidad, mientras que Erzt piensa en las riquezas que se olvidan al escuchar la música ${ }^{42}$. Desde luego, la presencia de armas, instrumentos y relojes apela al tema de las vanidades, tan querido por los pintores españo-

\footnotetext{
30 Alciato, Op. cit., pp. 133 y 134.

31 Cirlot, Op. cit., pp. 350 a 352.

32 Sebastián, Op. cit., p. 159.

33 Ripa, Op. cit., vol. I, p. 314.

34 Ripa, Op. cit., vol. II, p. 121.

35 Ripa, Op. cit., p. 246.

36 Ripa, Op. cit., vol. I, p. 87 y vol. II, p. 34.

37 Alciato, Op. cit., Emblema CLXXIX, p. 222.

38 Godwin, Joscelyn, Robert Fludd: Claves para una teología del Universo, Swan, Madrid, 1987, 171 pp., ver p. 86. Rowell, Op. cit., ver p. 100.

39 En el lienzo de El gusto, el oído y el tacto (Núm. 1404) la luz parece provenir del punto opuesto.

40 Montañés, Luis, «Relojes» en Historia de las artes aplicadas e industriales en España, coordinada por Antonio Bonet Correa, Cátedra, Madrid, 1982, 658 pp. Ver 181 y ss. Cfr. Hernández Parera, J., La pintura española y el reloj, Biblioteca literaria del relojero, VI, Madrid, 1958.

41 Díaz Padrón, Op. cit. Ver p. 43

42 Sabán Godoy y OO.AA., Op. cit. Cfr. Erzt, K., Jan Brueghel der Ältere (1568-1625). Die Gemälde mit kritischem Oeuvrekatalog, Colonia, 1979.
} 
les del XVII. Los relojes pueden además tener una sonería musical que acompañe los toques ${ }^{43}$. No hace falta mirar la hora, también se puede escuchar el paso del tiempo, oyendo el toque de las horas y los cuartos.

Junto a la silla de la ninfa encontramos dos armas de fuego: una pistola y un mosquete de rueda con chispa de pedernal ${ }^{44}$, aparatos ofensivos para la vida y el oído. La explosión repentina de la pólvora produce susto y sobresalto. Son mecanismos que en vez de medir el tiempo, marcan el instante que puede ser un final. Puesto que yacen en silencio, representan tiempo de paz ${ }^{45}$ correspondiente a la Tregua de los doce Años firmada por el Archiduque en 1609.

Un último y complejo mecanismo aparece en la pintura de Brueghel sobre la mesa de la derecha. Se trata de una esfera celeste con un lujoso soporte de bronce. Representa las constelaciones y está rematada por una pequeña esfera armilar con los planetas. Es un modelo del universo que alude al tiempo, como principio cósmico, y al paso de las estaciones. Cesare Ripa describe la Música acompañada de la esfera celeste como atributo propio ${ }^{46}$. En el sistema académico medieval era también patente la conexión entre la música y los conocimientos sobre la astronomía, las matemáticas y la geometría que se reunían en los estudios del Cuadrivium.

En conclusión, La alegoría del odio de Jan Brueghel de Velours hecha para los Archiduques de Austria contiene un complejo mensaje del cual podemos hacer la siguiente lectura:

\section{Reina la paz en los Países Bajos gracias a la Tregua de los doce Años}

Las armas yacen en silencio y solo se usan para caza y salvas de honor. El ciervo simboliza la longevidad (la vida eterna) y la paz duradera. Los clarines proclaman el poder de los Soberanos a los cuatro vientos.

Reina la concordia y la armonía: El laúd bien templado es símbolo de la armonía y la concordia. Suena la música bien templada y decorosa en todos los rincones y alcobas. Cantan las aves y anidan los gorriones y golondrinas en feliz convivencia. Impera la polifonía concertada de voces e instrumentos (cánones y madrigales).

Se suceden en paz las estaciones: Han llegado las aves migratorias y el verano va a comenzar. Giran las esferas celestes y pasan las estaciones. Los relojes marcan las horas de la Paz, el Orden y la Justicia.

Hay riqueza y abundancia: Llegan las garzas reales con los mejores augurios. Nos acompañan aves que nos recuerdan el Paraíso Terrenal. Los Archiduques patrocinan las artes (Minerva y las Musas, edición de madrigales) y coleccionan ricos objetos (relojes e instrumentos). Se ha reconstruido el Castillo de Mariemont que se ve al fondo.

\section{Ha triunfado el bien}

El ciervo es Cristo que ahuyenta al Demonio. Los animales se someten a la armonía (a la Ninfa, a Orfeo, a Arión).

Es tiempo para el amor honesto y divino: El amor será inmortal como el ciervo. Venus o

${ }^{43}$ Crowley, T. E., Discovering Mechanical Music, Shire Publications Ltd., 1975. Cfr. Ord-Hume, A. W. J. G., Clockwork Music, Allen \& Unwin, 1973.

${ }^{44}$ González de Amezúa, Mercedes, «Las armas en el teatro clásico español», en El Corral de Comedias, edición de David Castillejo, Teatro Español, Madrid, 1984, 315 pp. Ver pp. 239 a 254. "Armas y armaduras", en Historia de las artes aplicadas e industriales en España, coordinada por Antonio Bonet Correa, Cátedra, Madrid, 1982, 658 pp. Ver 171 y ss. Cfr. Casariego, Jesús E., Tratado histórico de armas, Labor, Barcelona, 1982.

45 Ripa, Op. cit., vol. II, p. 183 y ss.

46 Ripa, Op. cit., vol. II, p. 119 y ss. 
Erato aparece acompañadas de Cupido. Cupido promueve un Amor Virtuoso, pues se presenta sin sus flechas. La castidad triunfa con Orfeo retirado en Ródope.

Con la palabra, por el oído se fortalece la Fe católica: Escuchamos la palabra divina que es la salvación (Salmo 50 y Luc 11,28). Las profecías se cumplen con el nacimiento de Cristo (Luc 2,8. Luc 3. Mat 3). En la Encarnación la palabra se hizo carne (Luc 1,26). Las almas de los difuntos (las aves) van al cielo. Se guarda fidelidad a María (orante con perro). Cristo resucita como el ciervo y como Orfeo.

El oído es la fuente de todo conocimiento: La música vocal es superior a la música instrumental (Marsias). El oído presenta la verdad desnuda (la Ninfa está desnuda). La elocuencia musical todo lo puede (Orfeo y el papagayo). El oído supera en ocasiones a la vista (al lince). La esfera celeste se rige por la armonía divina y musical. Las partituras (la escritura) nos muestran la regla verdadera y el camino de la concordia.

Pero a veces conviene desconfiar: La Fama tiene dos trompas y llena los oídos de verdades y de mentiras. El ciervo, como el unicornio, a veces se deja apresar por la adulación. La riqueza y el poder solo son vanidades, pues todo pasa (relojes). Hay que limitar la elocuencia (el loro está en su jaula).

Y siguiendo tan sabio consejo, concluye aquí está interpretación musical y retórica de $L a$ Alegoría del Oído de Jan Brueghel «de Velours».

Víctor Pliego de Andrés Conservatorio «Arturo Soria» de Madrid

\section{EL GRABADO ITALIANO EN EL LIENZO «LA ADORACIÓN DE LOS REYES MAGOS», DE FRANCISCO CAMILO}

En 1914 fue depositado en el Museo de Bellas Artes de Bilbao un cuadro, donativo del ingeniero y conocido coleccionista de arte don Laureano de Jado ${ }^{1}$. En él se nos representa una escena del Nuevo Testamento, «La Adoración de los Reyes Magos» ${ }^{2}$ (Fig. 1), que, en el momento de su ingreso, estaba atribuido a Francisco Rizi. Estudios posteriores, tanto técnicos como estilísticos llevados a cabo por el profesor Diego Angulo Íñiguez ${ }^{3}$ a cerca de la obra completa del pintor Francisco Camilo (1615-1671) parecen no ofrecer duda alguna sobre la autoría de este lienzo por el artista madrileño. Incluso llegó a relacionar esta obra con otra que el propio Camilo realizó en una iglesia de la localidad castellana de Getafe y en general con toda la producción del artista pintor en donde se puede apreciar una importante influencia del mundo artístico ita-

1 Don Laureano de Jado, ingeniero de minas vinculado a los pueblos de Munguía y Erandio (donde se conservan instituciones a las que él contribuyó); fue un prestigioso coleccionista de arte y generoso donador que contribuyó de forma importante a la fundación del Museo de Bellas Artes de Bilbao (8 febrero 1914) y sobre todo a la amplicación de sus colecciones... Velez López, Oloina. "La creación del Museo de Bellas Artes de Bilbao», en Anuario del Museo de Bellas Artes de Bilbao, pp. 9-20 (1993).

2 "La Adoración de los Reyes Magos", atribuida a Francisco Camilo, ejecutada entre 1660-1670, óleo sobre lienzo 83. $119 \mathrm{~cm}$, donación de don Laureano de Jado, en 1914, n. ${ }^{\circ}$ inv. 69/43.

3 Angulo Íñiguez, Diego, "Un cuadro de Francisco Camilo en el Museo de Bellas Artes de Bilbao»; Archivo Español de Arte, n. ${ }^{\circ} 139,1962$, p. 271. 